\title{
Leishmania spp. PARASITE ISOLATION THROUGH INOCULATION OF PATIENT BIOPSY MACERATES IN INTERFERON GAMMA KNOCKOUT MICE
}

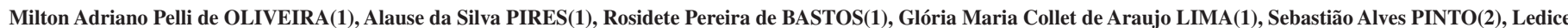

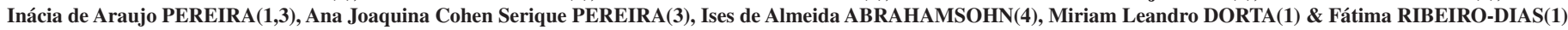

\begin{abstract}
SUMMARY
Isolation of Leishmania parasite and species identification are important for confirmation and to help define the epidemiology of the leishmaniasis. Mice are often used to isolate pathogens, but the most common mouse strains are resistant to infection with parasites from the Leishmania (Viannia) subgenus. In this study we tested the inoculation of interferon gamma knockout (IFN $\gamma \mathrm{KO}$ ) mice with biopsy macerates from Leishmania-infected patients to increase the possibility of isolating parasites. Biopsies from twenty five patients with clinical signs of leishmaniasis were taken and tested for the presence of parasites. Immunohistochemical assay (IHC) and conventional histopathology detected the parasite in $88 \%$ and $83 \%$ of the patients, respectively. Leishmania sp. were isolated in biopsy macerates from $52 \%$ of the patients by culture in Grace's insect medium, but $13 \%$ of isolates were lost due to contamination. Inoculation of macerates in IFN $\gamma \mathrm{KO}$ mice provides isolation of parasites in $31.8 \%$ of the biopsies. Most isolates belong to L. (Viannia) subgenus, as confirmed by PCR, except one that belongs to L. (Leishmania) subgenus. Our preliminary results support the use of IFN $\gamma$ KO mice to improve the possibility to isolate New World Leishmania species.
\end{abstract}

KEYWORDS: Leishmania (Viannia) subgenus; Leishmania isolation; Interferon gamma deficient mice; Leishmaniasis; Leishmania identification; Experimental leishmaniasis.

\section{INTRODUCTION}

Leishmaniasis is a zoonotic tropical disease present in four continents and is considered endemic in 88 countries, $82 \%$ of which are considered to be developing countries ${ }^{8}$. In Brazil, the incidence of leishmaniasis has increased during the last 20 years and many outbreaks in the South East, North East, Central, and more recently in the Amazonian region, have been reported ${ }^{3}$. According to the Brazilian Ministry of Health, during the period of 1985 to 2005 the annual average of new reported cases for the whole country was 28,568 . The Tropical Diseases Hospital $(\mathrm{TDH})$ in Goiânia, capital of the state of Goiás, is one of the reference hospitals for patients from the West and Central regions of Brazil, mainly those from Mato Grosso and Goiás states. The TDH also assists many patients from the neighboring States such as Tocantins and Pará (North region). The clinical forms of American tegumentary leishmaniasis (ATL) observed in patients coming from these areas include localized cutaneous leishmaniasis (LCL); diffuse cutaneous leishmaniasis (DCL); muco-cutaneous leishmaniasis (MCL) and visceral leishmaniasis (VL). The species of Leishmania so far identified by PCR and PCR-FLRP ${ }^{4,24}$ in this large area belong to the subgenera L. (Viannia) braziliensis, $L$. (Viannia) guyanensis or L. (Leishmania) amazonensis, isolated from LCL, DCL and MCL patients, and $L$. (L.) infantum chagasi isolated from VL patients (our unpublished results).
There are about 22 species of Leishmania that can infect human beings causing a broad clinical spectrum of cutaneous leishmaniasis ${ }^{4,19}$. A single species can often cause different clinical manifestations depending on the virulence of the parasite and the host resistance to the infection. On the other hand, some species are clearly associated with a worse prognosis and with more severe clinical manifestations of the disease. Therefore, while the detection of the parasite is sufficient for diagnostic purposes, the precise identification of the Leishmania species is important for epidemiological and clinical reasons, helping to investigate the pathogenesis of the different clinical forms of tegumentary leishmaniasis.

Traditionally, the species of Leishmania were identified on morphological grounds such as the parasite's size and the features of the vacuoles in infected macrophages. In addition, more complex approaches were used in research laboratories including the ability to grow in culture, development in the vector, electrophoretic mobility of different isoenzymes (zymodeme analyses) and the use of monoclonal antibodies (serodeme analyses) ${ }^{6,10,14}$. Molecular biology techniques have great potential to make the identification of Leishmania species more practical, quick and precise from material obtained directly from the skin lesions or from biopsies. The sensitivity of species-specific primers is worse than the primers for $\mathrm{kDNA}$, but is reliable for purposes of diagnosis ${ }^{17}$. However, isolation of the parasite before carrying out

(1) Instituto de Patologia Tropical e Saúde Pública, Universidade Federal de Goiás, Rua 235 S/N, 74605-050 Goiânia, Goiás, Brasil.

(2) Instituto Goiano de Oncologia e Hematologia, Rua 87 No 598, 74093-300 Goiânia, Goiás, Brasil.

(3) Hospital de Doenças Tropicais Anuar Auad, Av. Contorno S/N, 74853-120 Goiânia, Goiás, Brasil.

(4) Instituto de Ciências Biomédicas, Universidade de São Paulo, Av. Prof. Lineu Prestes 1730, 05508-900 São Paulo, SP, Brasil.

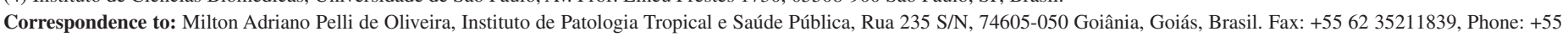
623209 6126. E-mail: mapoliv@usp.br 


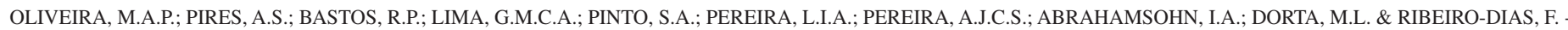
Leishmania spp. parasite isolation through inoculation of patient biopsy macerates in interferon gamma knockout mice. Rev. Inst. Med. Trop. Sao Paulo, 52(2):83-8, 2010.

species identification by molecular assays can increase the possibility of identifying the parasite. Moreover, isolates can be stored and be studied for the presence of virulence factors or resistance to drugs, and also for changes or adaptations that can occur within the species which are of obvious epidemiological importance.

Parasites are usually isolated in liquid or semi-solid culture media, but some species like $L$. (V.) braziliensis can be difficult to grow in culture medium ${ }^{12,13}$. Infections of experimental animals are additionally used to increase the chances of isolating the parasite; $\mathrm{BALB} / \mathrm{c}$ mice or hamsters are the most common laboratory animals used for this purpose ${ }^{23}$. Hamsters, although cumbersome to raise, are frequently used to isolate Leishmania because they are susceptible to practically all Leishmania species tested, whereas the most common mouse strains show varying degrees of susceptibility to the different parasite species and are, for instance, very resistant to $L$.(V.) braziliensis infection ${ }^{23}$.

Resistance to Leishmania infection, including L. (V.) braziliensis, depends on the ability of the host to synthesize adequate amounts of macrophage-activating cytokines, especially IFN $\gamma$. Mice that lack this cytokine are highly susceptible to Leishmania infection, including $L$. (V.) braziliensis infection ${ }^{7}$. Consequently, we tested IFN $\gamma$ knockout (IFN $\gamma \mathrm{KO}$ ) mice as an alternative host to isolate Leishmania from patient biopsies, a step to improve further species characterization and towards understanding the biology of the parasite. We propose that the inoculation of biopsy macerates in IFN $\gamma \mathrm{KO}$ mice can contribute to the isolation of Leishmania parasites.

\section{MATERIAL AND METHODS}

Patients: This study reports on a cohort of patients examined at the leishmaniasis outpatient (ambulatory care) service of the TDH, Goiânia, Brazil, between November 2005 and December 2006, presenting cutaneous or mucosal lesions and clinical history suggestive of leishmaniasis. All patients were volunteers, and informed consent was given prior to lesion biopsy, blood sample collecting and/or performing Montenegro skin test (MST). The patients came from endemic areas from Northern and Central regions of Brazil and had not been previously treated for leishmaniasis. Patients who tested positive in at least one of the tests for leishmaniasis were included in the cohort; patients whose tests were negative were excluded. The Ethical Committee for Human and Animal research of the "Hospital das Clínicas" of the Goiás Federal University approved all procedures reported in this study.

Animals: Female C57BL/6 wild type or C57BL/6 mice with disrupted IFN $\gamma$ genes (IFN $\gamma$ KO mice) were bred at the animal facilities of Federal University of Goiás/IPTSP, Brazil. IFN $\gamma \mathrm{KO}$ mice were originally purchased from Jackson Laboratories, ME/USA (B6.129S7-ifng ${ }^{\text {tmlTs }}$ ). The mice used were 6-12 weeks old and were maintained in a clean conventional mouse facility with ad libitum access to water and food.

Infection of mice with promastigotes isolates: Two isolates characterized as L. (Viannia) braziliensis (IMG3 (MHOM/BR/2003/ $\mathrm{IMG}^{L b}$ ) and RPL5 (MHOM/BR//2005/RPL $\left.{ }^{L b}\right)$ ) as described before ${ }^{26}$, were cultured for six days in 24-well culture plates kept at $26{ }^{\circ} \mathrm{C}$ in Grace's insect culture medium (Sigma Chemical Co., St. Louis, MO, USA) supplemented with $20 \%$ heat-inactivated fetal calf serum (FCS, Gibco BRL, Argentina), $2 \mathrm{mM}$ L-glutamine, $100 \mathrm{U} / \mathrm{mL}$ penicillin, and
$100 \mu / \mathrm{mL}$ streptomycin (referred to as Grace's complete medium). The parasites were washed with PBS and groups of four mice were injected subcutaneously with $5 \times 10^{6}$ live promastigotes into one of the hind footpads. Lesion size was measured during the course of infection with a dial micrometer and expressed as the difference in size between the infected footpad and the contralateral uninfected footpad. Following ethical procedures, when the footpad lesion reached 5 to $6 \mathrm{~mm}$ of thickness or presented ulceration, the mice were euthanized.

Isolation of Leishmania from human biopsies in mice: Biopsies were taken from the border of the lesion under local anesthesia using a $3 \mathrm{~mm}$ skin punch biopsy. The biopsy fragment was macerated in $0.5 \mathrm{~mL}$ sterile $0.15 \mathrm{M} \mathrm{NaCl}$ (saline) and $50 \mu \mathrm{L}$ of the suspension were inoculated into the dermis of both posterior footpads of one IFN $\gamma \mathrm{KO}$ mouse. The paws were inspected weekly until the $60^{\text {th }}$ day after inoculum or until the lesion reached 2 to $3 \mathrm{~mm}$. The animal was euthanized by $\mathrm{CO}_{2}$ inhalation and the footpads were aseptically collected, macerated and cultured in Grace's complete medium at $26^{\circ} \mathrm{C}$. The cultures were periodically examined for parasites.

Isolation of Leishmania from human biopsies in culture: Biopsies were macerated in $0.5 \mathrm{~mL}$ saline and $0.4 \mathrm{~mL}$ of the suspension was cultured in 24-well plates (Costar, Cambridge, MA, USA) in Grace's complete medium at $26^{\circ} \mathrm{C}$ for up to 30 days.

Montenegro skin test (MST): MST was performed using two similar antigen preparations, but from different laboratories (ISEP, Paraná, Brazil, and Laboratory of Leishmaniasis, Federal University of Minas Gerais, Brazil). They consisted of disrupted L. (L.) amazonensis (MHOM/BR/73/ M2269) containing $40 \mu \mathrm{g} / \mathrm{mL}$ of total nitrogen as described by MELO et al., $1977^{15}$. The antigen $(0.1 \mathrm{~mL})$ was injected intradermically (ID) into the forearm and the reaction was measured 72 hours after injection. The reaction was considered positive when induration at the site of injection was $\geq 5 \mathrm{~mm}$.

Indirect immunofluorescence reaction (IIF): Peripheral blood was collected and the serum underwent IIF reaction using promastigotes forms of L. (L.) amazonensis (IFLA/BR/67/PH8) to detect specific IgG antibodies using as secondary antibody, FITC-conjugated goat antihuman (IgG-specific) immunoglobulin (Bio-Mérieux).

Histopathology and immunohistochemistry (IHC) tests: Paraffinembedded $3 \mu \mathrm{m}$ tissue sections were stained using Hematoxylin-Eosin (H\&E), Giemsa Stain; Fite-Faraco method, periodic-acid Schiff (PAS) and Grocott's methenamine silver method or submitted to immunohistochemistry (IHC) with rabbit polyclonal antibodies antiLeishmania sp. (1/15000) (kindly supplied by Dr. Luis Antônio Freitas, Fiocruz, Bahia, Brazil). After overnight incubation with these antibodies, sections were treated with streptoavidin-biotin-peroxidase (kit-LSABplus, Dako, Glostrup, Denmark) followed by counterstaining with Mayer's hematoxylin. The whole section was screened for the presence of Leishmania under light microscopy at 400x magnification. The IHC-stained slides were semi quantitatively scored for the presence of Leishmania sp. antigen on a range of zero to 3 ; a score of zero corresponds to no staining, a score of 1 indicated up to $25 \%$ positively-stained cells, a score of 2 indicated $25-75 \%$ positive cells, a score of 3 indicated more than $75 \%$ of positive cells. 


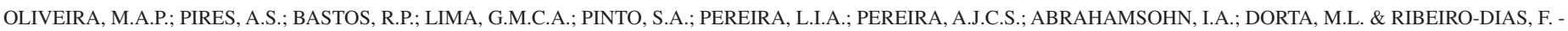
Leishmania spp. parasite isolation through inoculation of patient biopsy macerates in interferon gamma knockout mice. Rev. Inst. Med. Trop. Sao Paulo, 52(2):83-8, 2010.

Molecular characterization of parasites: Polymerase Chain Reaction (PCR): Genomic DNA of promastigotes isolates was obtained from stationary phase culture of parasites. The promastigotes were washed in phosphate-buffered saline ( $\mathrm{pH} 7.2)$ and the DNA was extracted by phenol/chloroform/iso-amyl alcohol (24:24:1) method and precipitated by isopropanol. After washing with $70 \%$ ethanol for $10 \mathrm{~min}$ at 10,000 , the DNA pellet was dissolved in ultra pure water containing RNAase $20 \mu \mathrm{g} / \mathrm{mL}^{21}$. Positive control reactions were performed with genomic DNA purified from axenic cultures of $L$. (L.) amazonensis, L. (V.) braziliensis, and negative controls without DNA. Sets of paired primers used in PCR assays to discriminate the subgenus L. (Viannia) and L. (Leishmania) were respectively G6PD-ISVA/ G6PD-ISVC and G6PD-ISLA/G6PD-F2, as described by CASTILHO et al. (2003) ${ }^{4}$.

Statistical Analyses: The number of positive samples for each diagnostic method was expressed in percentage and differences on the ability of each method to confirm leishmaniasis was analyzed by Fisher's exact test.

\section{RESULTS}

After infection of C57BL/6 mice or IFN $\gamma$ KO C57BL/6 mice with infective Leishmania (Viannia) braziliensis promastigotes isolated from two patients assisted at the TDH, it was observed that wild type C57BL/6 mice develop a small lesion that heals spontaneously (Fig. 1A). On the other hand, IFN $\gamma$ KO C57BL/6 mice develop an uncontrolled lesion that ulcerates four weeks after inoculum or reaches a size higher than $5 \mathrm{~mm}$ (Fig. 1B). These data indicates that IFN $\gamma$ KO C57BL/6 mice are highly susceptible to infection with $L$. (Viannia) parasites and could be used to isolate parasites from infected patients' biopsies.

To test that hypothesis, 37 patients admitted to the TDH presenting cutaneous or mucosal lesion with clinical history suggesting leishmaniasis were studied. Twenty five patients $(67.6 \%)$ were diagnosed as infected with Leishmania, and three of them developed the mucosal form of the disease (12\% of infected patients). For this study, patients were considered infected when clinical and epidemiological information was confirmed by at least one of the following diagnostic tests: isolation of parasites in culture or in mice, presence of the parasite by histopathological or IHC analysis, MST reaction above $5 \mathrm{~mm}$ or titer of IIF above 40. For technical reasons, it was not possible to use all methods to diagnose all patients. Parasites were observed in biopsies from 23 out of 25 infected patients ( $92 \%$ of infected patients) and two patients
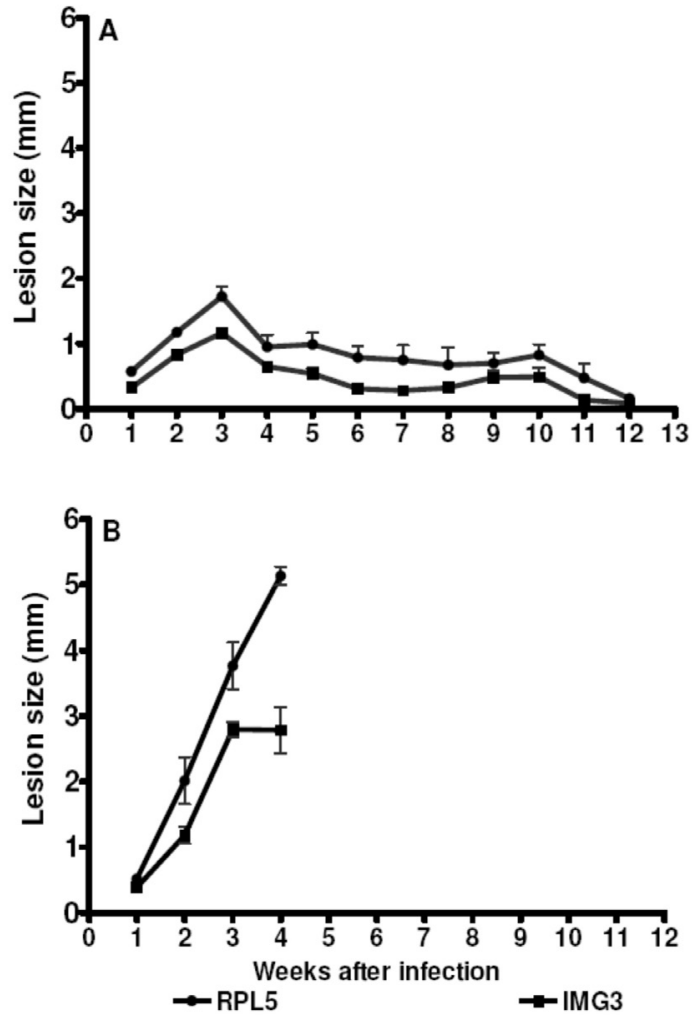

Fig. 1 - Time course of lesion development in C57BL/6 WT (A), IFN $\gamma$ KO C57BL/6 (B) mice infected with $5 \times 10^{6}$ stationary-phase promastigotes of isolates RPL5 and IMG3 in one of the hind footpads. The lesion size was expressed by subtraction of the thickness of contralateral uninfected paw from that of the infected paw. Data represent media \pm SEM.

were considered positive because of positive MST measuring $8 \mathrm{~mm}$ and $16 \mathrm{~mm}$. From the 12 patients who were diagnosed as non-infected by Leishmania, three had inconclusive laboratory exams, three had stasis ulcers, three had chronic dermatitis, two had ulcer of unknown etiology and one patient had vasculitis. None of these patients had any additional indication that the skin lesion could be caused by Leishmania infection. The IHC of biopsy sections was a very effective test to detect and diagnose leishmaniasis among the performed tests (Table 1). Microscopic examination of stained sections was as sensitive as IHC when both were compared by the statistical test. In one patient, the biopsy was diagnosed

Table 1

Absolute numbers and frequencies of ATL positivity by different diagnostic methods in a group of patients with American Tegumentary Leishmaniasis ${ }^{\mathrm{a}}$

\begin{tabular}{|c|c|c|c|c|c|c|}
\hline & Culture $^{b}$ & Mice $^{\mathrm{c}}$ & Histopathology ${ }^{d}$ & $\mathrm{IHC}^{\mathrm{e}}$ & $\mathrm{MST}^{\mathrm{f}}$ & $\mathrm{IIF}^{\mathrm{g}}$ \\
\hline Positives & $\begin{array}{c}13^{\mathrm{h}} \\
(52 \%)^{i *}\end{array}$ & $\begin{array}{c}7 \\
(31.8 \%)^{*}\end{array}$ & $\begin{array}{c}20 \\
(83.3 \%)\end{array}$ & $\begin{array}{c}15 \\
(88 \%)\end{array}$ & $\begin{array}{c}10 \\
(58.8 \%)\end{array}$ & $\begin{array}{c}9 \\
(47.3 \%)^{*}\end{array}$ \\
\hline Negatives & 12 & 15 & 4 & 2 & 7 & 10 \\
\hline Total performed ${ }^{j}$ & 25 & 22 & 24 & 17 & 17 & 19 \\
\hline
\end{tabular}

${ }^{a}$ Twenty five patients diagnosed as having ATL by at least one of different diagnostic methods; 'Observation of the parasite growing in Grace's insect medium inocu-

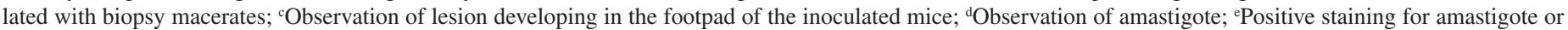
Leishmania antigen by immunohistochemistry (IHC); ${ }^{\mathrm{f}}$ Montenegro skin test (MST) measured 48 hours after intradermal injection of $L$. (L.) amazonensis antigen with

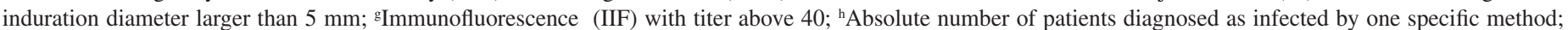
${ }^{i}$ Percentage of positive tests relative to the number of total tests performed ; ${ }^{\text {TTtal }}$ of patients who were submitted to that particular diagnostic method; * statistically different to/statistical difference of histopathology or ICH frequencies at $p<0.05$. 


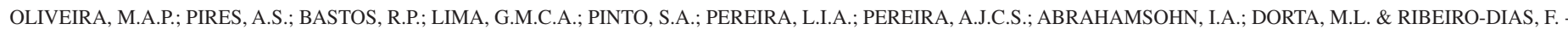
Leishmania spp. parasite isolation through inoculation of patient biopsy macerates in interferon gamma knockout mice. Rev. Inst. Med. Trop. Sao Paulo, 52(2):83-8, 2010.

Table 2

Highest densities of amastigotes in biopsies are associated with better detection rates of Leishmania in liquid culture or injected in IFN $\gamma \mathrm{KO}$ mice

\begin{tabular}{l|ccc}
\hline \multirow{2}{*}{$\begin{array}{l}\text { Number of biopsies } \\
\text { tested by IHC } \\
\text { for Leishmania sp }\end{array}$} & \multicolumn{3}{|c}{$\begin{array}{c}\text { Leishmania growth of } \\
\text { biopsy macerates inoculated in }\end{array}$} \\
\cline { 2 - 4 } & $\begin{array}{c}\text { Grace's culture } \\
\text { medium }\end{array}$ & $\begin{array}{c}\text { IFN } \gamma \text { KO } \\
\text { mice }\end{array}$ & $\begin{array}{c}\text { Time of lesion } \\
\text { (months) }\end{array}$ \\
\hline $\mathrm{n}=2^{\mathrm{a}}$ & 2 & 1 & 6 to $8^{\mathrm{d}}$ \\
$\mathrm{Score}^{\mathrm{b}}=0$ & 3 & 0 & $\begin{array}{c}2 \text { to } 7 \\
\text { Median }=6\end{array}$ \\
\hline $\mathrm{n}=6$ & 6 & 4 & $\begin{array}{c}2 \text { to } 8 \\
\text { Score }=1\end{array}$ \\
\hline $\mathrm{n}=8$ & 1 & 1 & Median $=5$ \\
\hline $\begin{array}{l}\text { Score }=2 \\
\mathrm{n}=1\end{array}$ & & & 5 \\
Score $=3$ & & & \\
\hline
\end{tabular}

$\overline{{ }^{a} \text { Number of biopsies that contain parasites and were evaluated by IHC. }{ }^{\mathrm{b}} \text { The scores }}$ represent the presence of Leishmania sp. in a range of 0 to 3 in IHC; a score of 0 corresponds to no staining, a score of 1 indicates up to $25 \%$ positively-stained cells, a score of 2 indicates $25-75 \%$ positive cells, a score of 3 indicates more than $75 \%$ of positive cells. ${ }^{\mathrm{c}}$ Number of biopsies in which parasites were isolated by inoculum in culture or in IFN $\gamma \mathrm{KO}$ mice, ${ }^{\mathrm{d}}$ duration of the lesion described by patient when biopsy fragment was collected.

as chronic dermatitis on conventional histopathology but scored positive for leishmaniasis when stained by IHC.

Biopsies from all 25 patients who were diagnosed as positive for ATL were cultured in Grace's complete medium (Table 1) and parasites were observed in 13 cultures (52\%); however, it was possible to recover parasites from 11 cultures (44\%), since the other two cultures were contaminated with bacteria or fungi. Biopsies from 22 patients with leishmaniasis were inoculated into the footpad of IFN $\gamma \mathrm{KO}$ mice and seven mice developed lesions (31.8\%). It is important to point out that those patients whose biopsy macerates induced Leishmania disease in IFN $\gamma$ KO mice, also had positive cultures when the biopsy material was directly cultured in Grace's medium. In four patients, parasites could be isolated in culture but inoculation in IFN $\gamma \mathrm{KO}$ mice did not cause visible lesions up to 60 days later. These four isolates were maintained in culture and parasites taken from these cultures, at the stationary phase, caused uncontrolled disease in IFN $\gamma \mathrm{KO}$ mice when inoculated $\left(5 \times 10^{6}\right.$ parasites) into the foot pad, showing that the IFN $\gamma \mathrm{KO}$ mice were indeed susceptible to these isolates (data not shown).

The higher scores of antigen positive cells by IHC seem to be associated with our ability to isolate parasites from cultures or in mice (Table 2). Hence, it was easier to isolate parasites by in vitro culture or by infection of IFN $\gamma \mathrm{KO}$ mice when biopsies scored 2 or 3 . However, we could isolate parasites in cultures from two biopsies that were negative by IHC, and in one of these, the macerate induced lesions in IFN $\gamma \mathrm{KO}$ mice (Table 2).

The time of the lesion informed by the patients was between two and eight months (Table 2; unpublished data), except for one patient, where lesion was present for more than two years and parasites were not isolated or observed in histopathology or IHC. The positivity for ATL in this patient was based on MST reaction above $15 \mathrm{~mm}$.
Six out of seven parasites isolated from mouse inoculation were characterized as belonging to L. (Viannia) subgenus and one belonging to L.(Leishmania) subgenus based on G6PD isoform found by PCR.

Three patients had mucosal lesions; of these, one had a positive MST above $8 \mathrm{~mm}$ and was not biopsied. Parasites were observed in the biopsy of one patient by IHC and in conventionally stained sections, but Leishmania could not be isolated from cultures or infected mice. The lesion of the third patient yielded parasites when cultured in Grace's but parasites were not seen in the sections even when stained by IHC.

\section{DISCUSSION}

Isolation of Leishmania parasites is useful for purposes of diagnosis but is mainly important for better understanding of clinical and ecoepidemiological aspects of leishmaniasis. Although there are no clear parameters that would allow us to predict whether the infection by one or other parasite would cause a more aggressive form of leishmaniasis, isolation of the parasites and their correct identification by molecular, biological or biochemical criteria is imperative in eco-epidemiological studies, especially because there are different Leishmania species and strains in nature ${ }^{12}$. The most common method to isolate Leishmania parasites is incubation of biopsies or lesions aspirates in culture medium.

Several culture media are used for this purpose, including Senekjie's medium containing bacto-beef-agar-peptone, solid blood agar medium, liquid Scheineider's or Grace's insect medium containing FCS, among others ${ }^{9,12,20,23,25}$. Additionally, different supplements have been incorporated to different media to improve culture and isolation of Leishmania, such as hemin ${ }^{18}$ or human urine ${ }^{1}$

We used Grace's insect medium supplemented with $20 \%$ of FCS and were able to isolate parasites from biopsies of more than $50 \%$ of infected patients. Isolation of Leishmania in culture medium in this study was more efficient than the data reported by some authors (e.g. 35\% reported by GUERRA et al., 2006 ${ }^{11}$ ) and more similar to the rates described by others, ranging from $35.8 \%$ to $54.7 \%^{2}$. However, there are reports in which isolation of Leishmania in culture medium achieved $90 \%$ of the material from infected patients 9 .

L. (V.) braziliensis is the most prevalent species causing leishmaniasis in our area (our unpublished results), and it has been described that this species is difficult to isolate in culture media. In addition, some strains of this parasite seem not to grow in culture or tend to lose the ability to proliferate after a few in vitro passages ${ }^{14,22,25}$ (our unpublished results). Based on these difficulties to isolate $L$. (V.) braziliensis and on the variation of the culture medium in different laboratories, it is understandable that the isolation of parasites in this work did not reach the highest rate reported by others.

When trying to isolate parasites by inoculum of biopsy macerates in culture, it is not uncommon to observe contamination due to bacteria and/ or fungi that come with biopsies ${ }^{25}$ (our results). To avoid lost of parasite due to contamination, the inoculation of aspirates or biopsy macerates in Syrian hamsters have been shown to be a useful method ${ }^{12,25}$. Inoculation of material from infected human tissue in hamsters showed positive results as high as $77.8 \%$ of leishmaniasis-confirmed patients ${ }^{25}$. Other authors were not able to obtain such high positivity rates, e.g., GUERRA et al., 


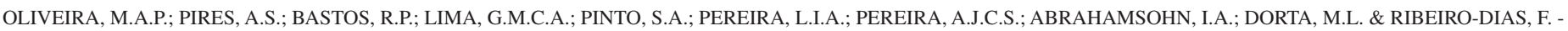
Leishmania spp. parasite isolation through inoculation of patient biopsy macerates in interferon gamma knockout mice. Rev. Inst. Med. Trop. Sao Paulo, 52(2):83-8, 2010.

2006 could isolate parasites from only $25 \%$ of the patients ${ }^{11}$. Interestingly, in a report by CUBA et al. (1996), it was shown that parasites were isolated more efficiently in culture media and only $57 \%$ of isolates were also capable of infecting hamsters ${ }^{5}$. It is accepted that mice are usually much less susceptible to some Leishmania species, particularly to those of the L. (Viannia) subgenus; on the other hand, IFN $\gamma$ deficient mice are highly susceptible to $L$. (V.) braziliensis infection ${ }^{7}$ (Fig. 1). Since many animal facilities can breed or maintain mice, but not all of them can keep other mammals, we proposed the inoculation of IFN $\gamma$ KO C57BL/6 mice as an additional method to isolate Leishmania from biopsies. Using this method we obtained success in only $37 \%$ of the biopsies from infected patients. Similarly to the data reported for hamsters by CUBA et al. $(1996)^{5}, 53.8 \%$ of biopsies which yielded parasites in liquid culture could also be isolated from IFN $\gamma \mathrm{KO}$ mice. This data suggests that the susceptibility of IFN $\gamma \mathrm{KO}$ mice is not different to the susceptibility of hamsters to isolate Leishmania sp. More importantly, our data shows that IFN $\gamma \mathrm{KO}$ mice can be used to isolate Leishmania parasites from $L$. (Viannia) subgenus, since six out seven isolates obtained from IFN $\gamma \mathrm{KO}$ mice belonged to L. (Viannia) subgenus.

Although a low rate of isolation of parasites was observed by using IFN $\gamma \mathrm{KO}$ mice in this study, this rate can be increased. In our experiments, we waited around eight weeks before euthanizing the mice to search for parasites, however, the lesions in hamsters was described to take from two to 12 weeks to develop after inoculation of patient material ${ }^{25}$. This data suggests that extension of the time to more than four weeks will probably increase the chance of isolating parasites. Indeed, during analysis of this report, we observed one mouse that developed lesion three months after inoculation of biopsy macerates and another six months after inoculation of biopsy macerates. Another way to improve the isolation rate in mice would be by increasing of the number of inoculated animals. We inoculated only one mouse (two paws) per biopsy macerate. It was reported that for less virulent strains of Leishmania, inoculation in hamsters fails to infect all animals of a group ${ }^{16}$.

The location, duration and size of lesion can also affect parasite isolation success. The biopsies used in this study were obtained from cutaneous or mucosal lesions with different sizes and duration between two and eight weeks. It was not possible to compare these parameters to the success of parasite isolation in this study. Nevertheless, we recently isolated parasites from three biopsies from patients with mucosal leishmaniasis (data not shown). The isolation of these parasites was only possible due to the use of IFN $\gamma$ KO mice, because the biopsies in culture medium were contaminated with fungi. It is described that patients with mucosal leishmaniasis usually have a low number of parasites in the lesion and isolation of parasites is difficult. This data reinforces the idea that the use of IFN $\gamma$ KO mice aids Leishmania isolation from biopsies.

The reason for the better isolation of parasites in culture media than animals is not clear at present, however it can be partially explained by differences in parasite species or strains and differences among the numbers of parasites in the samples ${ }^{14,23,25}$. It is possible that low amounts of parasites can be killed by the innate immune system, thus avoiding successful infection ${ }^{25}$. It is important to note that some strains of the parasite were described as unable to grow in hamsters ${ }^{14}$, but this resistance has not yet been described for IFN $\gamma \mathrm{KO}$ mice. The data in this study showed for the first time that mice are partially resistant to $L$.
(Viannia) subgenus by some mechanism independent of IFN $\gamma$, which is currently under investigation in our laboratories.

Our results support the idea that inoculation of biopsy macerates in IFN $\gamma$ KO mice can aid in isolating Leishmania mainly in facilities that are not prepared to maintain hamsters.

\section{RESUMO}

\section{Leishmania spp.: isolamento de parasitos pela inoculação de macerados de biopsias de pacientes em camundongos deficientes em interferon gama}

O isolamento e a identificação da espécie de parasito do gênero Leishmania são importantes para a confirmação e auxiliam na epidemiologia da leishmaniose. Os camundongos são freqüentemente utilizados para isolar patógenos, porém, as linhagens mais comuns de camundongos são resistentes à infecção por parasitos do subgênero Leishmania (Viannia). Neste estudo, avaliamos a inoculação de macerados de biópsias de pacientes infectados em camundongos deficientes do gene do interferon gama (IFN $\gamma \mathrm{KO}$ ) como um método para aumentar a possibilidade de isolar Leishmania spp. Biópsias de 25 pacientes infectados com Leishmania sp. foram avaliadas para a presença de parasitos pelos métodos de imunohistoquímica (IHC) e histopatologia convencional. Os parasitos foram observados, respectivamente, em $88 \%$ e $83 \%$ das biópsias. Leishmania sp. foi isolada de macerados de biópsia de $52 \%$ dos pacientes infectados, quando cultivados em meio Grace, porém, $13 \%$ destes isolados foram perdidos devido a contaminações. Inoculação dos macerados em camundongos IFN $\gamma \mathrm{KO}$ proporcionou o isolamento de parasitos oriundos de $31,8 \%$ dos pacientes. A maioria dos isolados pertence ao subgênero L. (Viannia), exceto um que pertence ao subgênero L. (Leishmania), como confirmado pela reação da polimerase em cadeia. Nossos resultados preliminares sugerem que o uso de camundongos IFN $\gamma \mathrm{KO}$ pode ser útil para aumentar a possibilidade de isolamento de leishmânias encontradas nas Américas.

\section{ACKNOWLEDGEMENTS}

We are indebted to Dr. L. Q. Vieira and Mr. Antonio Vaz Mesquita (UFMG) for providing C57BL/6 IFN $\gamma \mathrm{KO}$ and for reviewing the manuscript. Financial support: This work was supported by $\mathrm{CNPq}$, CAPES, Funape/UFG, FAPEG (Dr. Fátima Ribeiro-Dias 02/2007), and SECTEC/GO/CNPq (Dr. Glória Maria Collet de Araújo Lima, grant 68.0067/2004-3), Brazil.

\section{REFERENCES}

1. Armstrong TC, Patterson JI. Cultivation of Leishmania braziliensis in an economical serum-free medium containing human urine. J Parasitol. 1994;80:1030-2.

2. Boggild AK, Miranda-Verastegui C, Espinosa D, Arevalo J, Adaui V, Tulliano G, et al. Evaluation of a microculture method for isolation of Leishmania parasites from cutaneous lesions of patients in Peru. J Clin Microbiol. 2007;45:3680-4.

3. Brasil. Ministério da Saúde. Manual de vigilância da leishmaniose tegumentar americana Brasilia: Ministério da Saúde; 2007

4. Castilho TM, Shaw JJ, Floeter-Winter LM. New PCR assay using glucose-6phosphate dehydrogenase for identification of Leishmania species. J Clin Microbiol. 2003;41:540-6. 
OLIVEIRA, M.A.P.; PIRES, A.S.; BASTOS, R.P.; LIMA, G.M.C.A.; PINTO, S.A.; PEREIRA, L.I.A.; PEREIRA, A.J.C.S.; ABRAHAMSOHN, I.A.; DORTA, M.L. \& RIBEIRO-DIAS, F. Leishmania spp. parasite isolation through inoculation of patient biopsy macerates in interferon gamma knockout mice. Rev. Inst. Med. Trop. Sao Paulo, 52(2):83-8, 2010.

5. Cuba CA, Torno CO, Ledesma O, Visciarelli E, Garcia S, Prat MI, et al. Human cutaneous leishmaniasis caused by Leishmania (Viannia) braziliensis in Santiago del Estero, Argentina: identification of parasites by monoclonal antibodies and isoenzymes. Rev Inst Med Trop Sao Paulo. 1996;38:413-21.

6. Dantas-Torres F. Final comments on an interesting taxonomic dilemma: Leishmania infantum versus Leishmania infantum chagasi. Mem Inst Oswaldo Cruz. 2006;101:929-30

7. De Souza-Neto SM, Carneiro CM, Vieira LQ, Afonso LC. Leishmania braziliensis: partial control of experimental infection by interleukin-12 p40 deficient mice. Mem Inst Oswaldo Cruz. 2004;99:289-94.

8. Desjeux P. Leishmaniasis: current situation and new perspectives. Comp Immunol Microbiol Infect Dis. 2004;27:305-18.

9. Escobar MA, Martinez F, Scott Smith D, Palma GI. American cutaneous and mucocutaneous leishmaniasis (tegumentary): a diagnostic challenge. Trop Doct. 1992;22(Suppl 1):69-78;63-64

10. Grimaldi Jr G, Tesh RB, Mcmahon-Pratt D. A review of the geographic distribution and epidemiology of leishmaniasis in the New World. Am J Trop Med Hyg. 1989;41:687725.

11. Guerra JADO, Ribeiro JAS, Coelho LI, Barbosa MG, Paes MG. Epidemiologia da leishmaniose tegumentar na comunidade de São João, Manaus, Amazonas, Brasil. Cad Saúde Públ. 2006;22:2319-27.

12. Lainson R, Shaw JJ, Silveira FT, de Souza AA, Braga RR, Ishikawa EA. The dermal leishmaniases of Brazil, with special reference to the eco-epidemiology of the disease in Amazonia. Mem Inst Oswaldo Cruz. 1994;89:435-43.

13. Lemesre JL, Darcy F, Kweider M, Capron A, Santoro F. Requirements of defined cultivation conditions for standard growth of Leishmania promastigotes in vitro. Acta Trop. 1988:45:99-108.

14. Manson-Bahr P. Diagnosis. In: Peters W, Killick-Kendric, R. The leishmaniasis in biology and medicine. London: Academic Press; 1987. p.703-31

15. Melo MN, Mayrink W, da Costa CA, Magalhães PA, Dias M, Williams P. et al.Padronização do antígeno de Montenegro. Rev Inst Med Trop Sao Paulo. 1977;19:161-
16. Melo MN, Williams P, Rocha NM, Babá EH, Mayrink W, Michalick MS, et al. The change of behaviour of two strains of Leishmania after cultivation in a defined medium. Mem Inst Oswaldo Cruz. 1987;82:557-61.

17. Ovalle Bracho C, Porras De Quintana L, Muvdi Arenas S, Rios Parra M. Polymerase chain reaction with two molecular targets in mucosal leishmaniasis' diagnosis: a validation study. Mem Inst Oswaldo Cruz. 2007;102:549-54

18. Pal JK, Joshi-Purandare M. Dose-dependent differential effect of hemin on protein synthesis and cell proliferation in Leishmania donovani promastigotes cultured in vitro. J Biosci. 2001;26:225-31.

19. Reithinger R, Dujardin JC, Louzir H, Pirmez C, Alexander B, Brooker S. Cutaneous leishmaniasis. Lancet Infect Dis. 2007;7: 581-96.

20. Sacks DL, Hieny S, Sher A. Identification of cell surface carbohydrate and antigenic changes between noninfective and infective developmental stages of Leishmania major promastigotes. J Immunol. 1985;135:564-9.

21. Sambrook J, Fritsch EF, Maniatis T. Molecular cloning: a laboratory manual. New York Cold Spring Harbor Laboratory Press; 1989.

22. Shaw JJ, Lainson $\mathrm{R}$. The in vitro cultivation of members of the Leishmania braziliensis complex. Trans R Soc Trop Med Hyg. 1981;75:127.

23. Singh S. New developments in diagnosis of leishmaniasis. Indian J Med Res. 2006;123:311-30.

24. Volpini AC, Passos VM, Oliveira GC, Romanha AJ. PCR-RFLP to identify Leishmania (Viannia) braziliensis and L. (Leishmania) amazonensis causing American cutaneous leishmaniasis. Acta Trop. 2004;90:31-7.

25. Weigle KA, De Dávalos M, Heredia P, Molineros r, Saravia NG, D’Alessandro A. Diagnosis of cutaneous and mucocutaneous leishmaniasis in Colombia: a comparison of seven methods. Am J Trop Med Hyg. 1987;36:489-96.

26. Zauli-Nascimento RC, Miguel DC, Yokoyama-Yasunaka JKU, Pereira LIA, Oliveira MAP, Ribeiro-Dias F, et al. In vitro sensitivity of Leishmania (Viannia) braziliensis and Leishmania (Leishmania) amazonensis Brazilian isolates to meglumine antimoniate and amphotericin B. Trop Med Int Health. 2010;15:68-76.

Received: 4 May 2009

Accepted: 27 January 2010 